\title{
Analysis and Application of Emotional Factors in Product Design
}

\author{
Luo Lihe \\ Beijing Normal University, Zhuhai
}

Keywords: Product, Design, Emotion

\begin{abstract}
Chinese economy has been developing rapidly ever since reform and opening up, and people's living standard is also improving day by day. Therefore, the quality of people's material life has been rising greatly, and people's demands on product design have been increasingly higher, which on the one hand, is represented in the design of product functions and appearance; on the other hand, it is represented in emotional factors of product design. The existence of emotional factors in product design is an important factor that makes the product different from everything else and it endows the product with vitality; in the meantime, it can arouse people's acknowledgement and favor to product design to the greatest extent. Under such circumstances, analysis and application of emotional factors in product design becomes important. This paper mainly states how to express different emotions and endow them with vitality and creativity by product design from the perspective of specific presentation of emotional factors of product design.
\end{abstract}

\section{Introduction}

With Chinese economy leaping to be the world's second largest economy, the quality of people's life has become increasingly higher, and the expression of people's emotions is also becoming increasingly more individual. Therefore, product is not merely to satisfy consumers' basic usage functions, it is more about presenting oneself and expressing oneself by emotions presented in product design. In such background, product design for emotional appeal is born at the right moment. After expressing emotional appeal by different design philosophies, people's demands on product individuation have been higher and higher. Therefore, product subdivision becomes more subdivided gradually.

\section{Embodiment of emotional factors in product design}

In visual effects, functions brought by colors are very important. By the colorful colors and collocation, various different information transmission can be formed. As an indispensable article for use in people's daily life, shoes transmit the person's favor, personality and other information by cooperation between color and modeling. It is an important carrier of information transmission based on colors.

Because of long time of life experience, when people are watching different colors, they would have different psychological discrepancies. For example, people believe that yellow stands for vivacious, lively and enthusiastic; while they believe purple stands for elegant, noble and mysterious. However, people's cognition of colors would also vary because of different countries. For example, white in China stands for ill omen, while Westerners believe white stands for purity. In China, red stands for jubilance, while in the West, it stands for alert, and it is not auspicious. Therefore, when applied in different countries and areas, different colors would be different. However, generally speaking, people's cognition of colors in different countries and areas is becoming increasingly more tolerant, i.e., when reserving their own cognition, they can also take in other understanding of colors.

Кандинский published his monograph Dots, Lines and Faces_—Bases of Abstract Art in 1926. In the book, he proposed that the inner demands of art should be embodied in dots, lines, faces and 
colors, thereby expressing maestro's artistic thoughts. The book focuses on the inner values of "lines", which is one of the abstract art language elements. About the creation of "lines", Кандинский states clearly that "In geometry, line is an invisible object. It is a tract left by moving dot. Therefore, it is born by movement. Indeed, it is created by destroying the final static condition of dot. Therefore, line is a result opposite to basic painting elements. Strictly speaking, it can be called the second element." The master analyzed the basic types and characteristics of lines in geometry in the way of tension and direction from purely rational perspective.

Here, we call the dots, faces and lines of Кандинский by a joint name of lines, since generalized lines from dots to lines to faces can all start from lines and finish with lines. In product design, usage of lines can also embody corresponding emotional factors. For example, straightforward people are more likely to choose lines when selecting products, and most men belong to this type. When women are choosing products, they would probably choose curved ones, which can represent tactful and mellow female characteristics. These are different emotional appeals and expressions that can be brought by lines. For example, in the design of architecture products, most of them are designed with straight lines, and most of the buildings in universities are like this. However, teaching buildings in art schools are not so. They would be more varied in the choice of lines instead of straight lines in order to manifest artistic smells.

Individualized design is a design way targeting at the psychological characteristics of existing target groups during product design, and it can embody the emotions of products clearer. If the emotions of color and lines are not embodied so clearly, application of emotion in individualized design is prominent.

\section{Analysis of the application of emotional factor in product design}

Because of differences of texture and modeling, color matching during design of boots and shoes would be influenced a little. No matter from lines, colors, modeling, texture and other aspects, color matching of boots and shoes should be considered from aesthetics, mechanics, plasticism, chromatics and so on.

Firstly, because of the particularity of the modeling of boots and shoes, usage of simple colors should be valued during color matching. First of all, color matching of boots and shoes should be as concise as possible. Too complicated color matching would cause visual encumbrance in turn. Therefore, color matching of boots and shoes should be single color or within 3 types of colors. Even if several colors are adopted for matching, the colors should be matched. Special attention should be paid to avoid strongly unsuitable colors, and harmony between colors of boots and shoes and the whole costume should be considered.

As for color matching talked in the above parts, good tonal perception should be considered. Tonal perception refers to the basic characteristics of a color in a certain sense organ. Tonality is determined by hue, lightness and purity. Different hue, lightness and purity would create subtle influences on tonality of colors, and this is the secret that you can see multiple types of color matching among different boots and shoes. Different tonality can bring different sensorial effects to consumers and embody designers' design thoughts, intention and interests, etc., thereby causing communication resonance between consumers and designers, and color is a crucial bridge.

From the perspective of lines, the application of lines has different emotional significance in different fields. Take the same straight lines for example. If a large number of straight-line product composition appear in a movie, people would feel that the movie is direct and cold. If large numbers of straight lines or sections appear in architectural product design, it would bring scientific and cool sense. Take another thing for example, children's toys usually have soft lines not only because security risks to children would be reduced as much as possible, but also because children have simple and acute emotions as emotionally externalized human animals. However, generally speaking, boys' toys usually have more straight and hard lines than those of girls, which is mainly because of natural instincts. Boys and girls have some naturally differences at their birth. Therefore, during product design, emotional appeals for men's and women's product design are different, which is a conventional philosophy and behavior manual instruction in product design. 
People's emotional appeals for product design are usually out of their yearnings for inner expression and communication and attention for external information. Therefore, no matter how product of emotional appeals is conducted in specific designs, product of emotional appeals should first start from humanized perspective, pay attention to consumers' psychology as well as the information they want to express and acquire; it should render them humanized care and understand their emotional appeals for products, thereby making product design that can truly satisfy emotional appeal.

Another important route for product design of emotional appeal is to break the routine, i.e., including artistic conceptions that exist in people's life but have some distance with life into product design to bring art, literature, poems, emotions and so on closer to people. Through specific designs, these emotional appeals can appear around consumers for real, and they appear in the way of common daily necessities, thereby shortening the distance between dream and reality, truth and fantasy and reaching harmonious beauty.

In product design of emotional appeal, exaggeration is a common pattern of manifestation, since emotional expression is related to exaggeration in essence. The natural purpose of exaggeration is to strengthen the expression of a certain emotion by a special expression way; meanwhile, through exaggerated manifestation, this emotional appeal can be embodied strongly and better effects of emotional appeal can be acquired.

Previous product design usually lacks humanity and emotional individuality. Take bags and suitcases design for example. Previous design is usually internal and external pocket, and a zipper or a cover is used as the opening of the bag. With design development of various hardware in the market, structure of bags and suitcases is broken and recombined by changing the connection mode, hidden structure and so on; dots, lines and faces are grasped in general, thereby reaching good combination, and structure of bags and suitcases becomes increasingly more interesting. Therefore, bags and suitcases are collapsible and stretching, and the spaces they take up can either be large or small, so consumers' usage experience is enriched.

Decorations in the design of traditional bags and suitcases can be divided into two-dimensional and three-dimensional. Contents in two-dimensional decorations include animals, plants, humans, etc., and they can expand continuously on the flat; three-dimensional decorations include various three-dimensional geometric figures, irregular figures, popular cultural symbols, etc. The existence of two-dimensional and three-dimensional decorations play critical importance in expressing more individualized emotional appeals in product design.

No matter it is the matching and using of colors or the using of lines or decoration, they are all based on creative design; meanwhile, only in this way can product design innovate continuously. In the meantime, in the background of new age, various materials keep emerging, especially the emergence of new materials has provided more possibilities for product design, and designers have large innovation space. Under such circumstances, when designers are designing, they must dare to innovate and try, explore people's emotional demands and emotional expectation for products continuously, and combine the style, characteristics and functions of materials organically. Appropriate application of materials can make the finishing point in the expression of the product's emotional factors.

\section{Conclusion}

Emotional factor in product design is mainly through designs of colors, lines and individuation. During the process that colors embody emotional factors, choice of color base and mixture and matching of different colors are used to create better emotional expression for product design. From the perspective of lines, different demands should be taken into consideration to choose different lines, thereby better presenting emotions. Personalized design is both a mainstream and subdivided direction in product design; it can conduct customized design by trying to figure out consumers' psychology carefully, thereby forming a good emotional interaction between products and consumers and strengthening their acknowledgement to product design. The above are some important common factors in emotional factors of product design. Specific analysis is made on the 
application of them in this paper in the hope that it can provide some reference for everyone.

\section{References}

[1] Zheng Simin. A Research on the Importance of Emotional Expression in Product Design [J]. Views on Art.2016(05)

[2] Zhao Yueyang. Exploration on Material Sharing in Product Design [J]. Popular Literature. 2016(09)

[3] Hu Yuxia, Li Zhiying. On Innovative Approaches of Product Design [J]. Views on Art.2016(06)

Introduction to the author: Luo Lihe, male, born in Hunan Province in May, 1979, education background: postgraduate, work unit: Beijing Normal University, Zhuhai, lecturer, research direction: product modeling and creative design. 